\title{
SPECIAL REVIEW
}

\section{Reconceptualising the beta diversity-environmental heterogeneity relationship in running water systems}

\author{
JANI HEINO*, ADRIANO S. MELO ${ }^{\dagger}$ AND LUIS M. BINI ${ }^{\dagger}$ \\ *Finnish Environment Institute, Natural Environment Centre, Biodiversity, Oulu, Finland \\ †Departamento de Ecologia, Universidade Federal de Goiás, Goiânia, Brazil
}

\section{SUMMARY}

1. Beta diversity modelling has received increased interest recently. There are multiple definitions of beta diversity, but here, we focus on variability in species composition among sampling units within a given area. This facet can be described using various approaches. Some approaches ignore the spatial scale of the area considered (i.e. region limits), while some consider different region limits as a starting point for the analysis of beta diversity.

2. We focused specifically on the beta diversity-environmental heterogeneity relationship in running waters. First, we present two conceptual models, which assume either (1) strong environmental control among localities (riffle sites in our case) within each region unit (a region unit encompasses a species pool and can be a stream or a basin or an ecoregion) or (2) that the spatial level of a region unit affects the relative importance of mechanisms affecting variability in species composition among localities (i.e. among riffle sites) within each region unit. Second, we compared three recent studies that used similar methods to examine the beta diversity-environmental heterogeneity relationship, but which were based on different region units, comprising sets of streams or sets of basins or sets of ecoregions.

3. Our conceptual framework assumes that environmental control is not likely to be the sole mechanism affecting variability in community composition among localities within each region unit, but it is likely to be most important when dispersal rates are intermediate (i.e. among localities within a basin). In contrast, if dispersal rates are very high (i.e. among localities within a stream) or very low (i.e. among localities within an ecoregion), environmental control is in part masked by high dispersal rates or is prevented from occurring because not all species can reach all localities, respectively. Such scale dependency in the relative strength of environmental control might therefore transcend spatial scales from individual region units to the strength of the beta diversity-environmental heterogeneity relationship. We emphasise that the beta diversity-environmental heterogeneity relationship can only be tested across multiple region units. The results of three case studies are consistent with these predictions. Specifically, the beta diversity-environmental heterogeneity regression was highly significant across multiple basins, but not across multiple streams or across multiple ecoregions.

4. We suggest that researchers take spatial scale and region unit level explicitly into account when inferring the mechanisms structuring ecological communities and mapping variation in beta diversity. We also propose a unified terminology for studies examining the beta diversity-environmental heterogeneity relationship in running waters because inconsistent terminology is likely to hamper the progress of our science.

Keywords: average distance to centroid, dispersal, spatial scale, species sorting, terminology

Correspondence: Jani Heino, Finnish Environment Institute, Natural Environment Centre, Biodiversity, Paavo Havaksen Tie 3, FI-90014 Oulu, Finland.

E-mail: jani.heino@environment.fi 


\section{Introduction}

Species diversity can be described by three components: local species richness ( $\alpha$-diversity), regional richness $(\gamma$-diversity) and differences in species composition between localities ( $\beta$-diversity) (Whittaker, 1960). While a large number of studies have focused on local or regional species richness patterns in the past, ecological research has shifted much of its recent focus to beta diversity patterns (Anderson et al., 2011; Melo et al., 2011). There are various beta diversity concepts (Tuomisto, 2010; Anderson et al., 2011), but in this paper, we favour the one proposed by Anderson, Ellingsen \& McArdle (2006) owing to its simplicity: 'Beta diversity can be defined as the variability in species composition among sampling units for a given area'.

In the context of studying beta diversity, the concepts of 'region unit' and 'locality' are important (Table 1). Among the factors accounting for variation in beta diversity across multiple region units, environmental heterogeneity (here defined as the variation in abiotic conditions among the same set of localities where beta diversity was estimated within a region unit; Fig. 1) is often hypothesised as being of paramount importance (Anderson et al., 2006). One could expect a positive beta diversity-environmental heterogeneity relationship (BDEHR) because an increase in the latter incorporates an increase in the variety of environmental conditions to which different species are adapted, hence producing greater variation in species composition among localities within a region unit (Chase \& Leibold, 2003; Leibold et al., 2004). Despite its intuitive appeal, however, this explanation has not gained unequivocal empirical support. As with the alpha diversity-environmental heterogeneity relationship (Bar-Massada \& Wood, 2014), the BDEHR may also show multiple forms. The potential reasons underlying different BDEHRs centre on issues of (1) spatial level of a region unit, (2) environmental gradient length and (3) ecological mechanisms, the importance of which may be determined by a combination of (1) and (2). These differences may also be affected by (4) statistical choices. Furthermore, communication of research findings is hampered by inconsistent terminology and, hence, we propose a unified terminology for this field of research (Table 1).

Table 1 Definitions of the common terms used throughout this paper

\begin{tabular}{|c|c|}
\hline Term & Definition \\
\hline Spatial grain & $\begin{array}{l}\text { Spatial grain refers to the size of the sampling unit used in a study (Wiens, 1989). In running water research, spatial } \\
\text { grain typically refers to the local arena, such as a riffle site, in macroecological studies (Heino, 2011) }\end{array}$ \\
\hline Spatial extent & $\begin{array}{l}\text { Spatial extent refers to the size of the region encompassing all localities in a region unit (Wiens, 1989). Spatial } \\
\text { extent can be measured as the distance between the localities situated furthest from each other or as a convex } \\
\text { polygon encompassing all localities in a region unit }\end{array}$ \\
\hline Region unit level & $\begin{array}{l}\text { A region unit encompasses a regional species pool. In running waters, a region unit may be a stream (Grönroos \& } \\
\text { Heino, 2012), a drainage basin (Landeiro et al., 2012) or an ecoregion (Bini et al., 2014) }\end{array}$ \\
\hline Locality & $\begin{array}{l}\text { A locality is a local arena within which biotic interactions and responses of species to environmental conditions } \\
\text { occur. A locality harbours a biological community. In running water research, a typical locality is a riffle site } \\
\text { (Heino, 2011) }\end{array}$ \\
\hline $\begin{array}{l}\text { Environmental } \\
\text { conditions }\end{array}$ & Environmental features of a locality. Environmental factors are agents of species sorting (Leibold et al., 2004) \\
\hline Beta diversity & $\begin{array}{l}\text { Biological differences among two or more localities. In this study, we define beta diversity as variability in species } \\
\text { composition among localities within a region unit (Anderson et al., 2006) }\end{array}$ \\
\hline Species sorting & $\begin{array}{l}\text { Species are filtered by environmental factors to occur at environmentally suitable sites. Adequate dispersal rates are } \\
\text { necessary so that species can track variation in environmental conditions among localities (Leibold et al., 2004) }\end{array}$ \\
\hline Mass effects & $\begin{array}{l}\text { High dispersal rates homogenise community structure at adjacent localities irrespective of their environmental } \\
\text { conditions and obscure species sorting (Leibold et al., 2004) }\end{array}$ \\
\hline Dispersal limitation & $\begin{array}{l}\text { Some species are precluded from occurring at suitable localities because the nearest occupiable sites are too far } \\
\text { away. Dispersal limitation prevents perfect species sorting from occurring because species cannot reach all } \\
\text { environmentally suitable localities (Leibold et al., 2004) }\end{array}$ \\
\hline Dispersal barrier & $\begin{array}{l}\text { Any factor (e.g. geomorphological, hydrological) that prevents species from dispersing to all localities within a } \\
\text { region unit }\end{array}$ \\
\hline
\end{tabular}


Spatial scale is a key issue in ecology because most patterns and underlying processes are scale dependent (Levin, 1992; Wu \& Loucks, 1995). Spatial scale comprises 'grain', which refers to the resolution or size of the sampling unit, and 'extent', which refers to the size of the region encompassing all sampling units of a study (Wiens, 1989). A change in either grain or extent is expected to change beta diversity patterns (Barton et al., 2013), and a number of studies have shown that beta diversity is strongly dependent on the grain size and the spatial extent of a study (Gering \& Crist, 2002; Hepp \& Melo, 2013).

Along with increasing spatial extent, ranges in environmental variables are also likely to increase (e.g. Jackson, Peres-Neto \& Olden, 2001), so ecologists have also used spatial extent or geographic distances between sites as surrogates for environmental heterogeneity (e.g. Harrison, Ross \& Lawton, 1992). Increasing lengths of environmental gradients are likely to increase the strength of environmental filtering (i.e. species sorting), and one may expect to find increasingly large variation in species composition with increasing spatial extent due to the increased importance of species sorting (e.g. Heino, 2011). Thus, although dispersal rates are also likely to be scale dependent (e.g. Ng, Carr \& Cottenie, 2009), their effects may go unnoticed because the lengths of environmental gradients may increase with increasing spatial extent.

Our definition of region unit is a key issue in this context. In running water research, a region unit of analysis may refer to a stream encompassing multiple riffle sites (Grönroos \& Heino, 2012; Al-Shami et al., 2013), a drainage basin encompassing multiple stream riffle sites (Landeiro et al., 2012; Göthe, Angeler \& Sandin, 2013) or an ecoregion encompassing multiple stream riffle sites from different drainage basins (Mykrä, Heino \& Muotka, 2007; Bini et al., 2014). In all these studies in running waters, grain size was a riffle site, whereas the region unit of analysis varied among studies, being a stream, a drainage basin or an ecoregion, respectively. In the following, we will refer explicitly to grain size as a locality (riffle site) and the three levels as region units. We emphasise that 'spatial level of a region unit' and 'spatial extent' are not exactly the same thing. Although spatial extent does increase from the stream level to the ecoregion level, spatial extent may also vary within each region unit level (e.g. ecoregions of different sizes; Bini et al., 2014).

Two different conceptual models can be used to illustrate the scale dependency of the BDEHR. First, 'the environmental control model' underlying variation in beta diversity across multiple region units assumes that the spatial level of a region unit has no effect on the mechanisms underlying the BDEHR (Fig. 2). This model starts from within each region unit, where species sorting is occurring among localities. Species are assumed to be able to disperse to all localities within a region unit and, hence, environmental conditions determine which species are able to occur at a locality (Leibold et al., 2004). Species sorting should be the more important the wider the differences in environmental conditions are among localities within a region unit. If this model holds within each region unit, one may also expect a positive BDEHR that can only be detected across multiple region units. An important consideration in this context is, however, that the region unit level within which both beta diversity and habitat heterogeneity are measured typically varies among studies (Fig. 1).

Simultaneous consideration of the spatial level of a region unit, dispersal rates, spatial extent and environmental gradient lengths is important because these factors determine the relative roles of the mechanisms structuring ecological communities (Leibold et al., 2004; Gravel et al., 2006; Thompson \& Townsend, 2006; Brown et al., 2011; Altermatt, 2013; Bini et al., 2014; Datry et al., 2014). The main general mechanisms causing variation in community composition among localities within a region unit include not only species sorting but also mass effects at small spatial extents and dispersal limitation at large spatial extents (Table 1). These two dispersal-related mechanisms may obscure species sorting effects by disassociating species and the environment owing to either very high or very low dispersal rates (Leibold et al., 2004; Ng et al., 2009; Winegardner et al., 2012; Heino \& Peckarsky, 2014). Species sorting has been shown to be the most important mechanism structuring ecological communities at various spatial extents (Cottenie, 2005; Van der Gucht et al., 2007), including stream systems ranging from riffle to catchment extents (Robson, 1996; Downes et al., 1998; Robson \& Chester, 1999; Landeiro et al., 2012). However, the potential scale dependencies of species sorting, mass effects and dispersal limitation have received little explicit consideration in running waters (Heino, 2013; Heino \& Peckarsky, 2014), although some studies have considered those mechanisms at very small extents within and among riffles in a stream (Robson \& Chester, 1999; Downes \& Reich, 2008; Downes \& Lancaster, 2010). Furthermore, those dispersal-related mechanisms acting among localities within each region unit are likely to affect the BDEHR. For example, mass effects may mask the effects of species sorting among localities within 


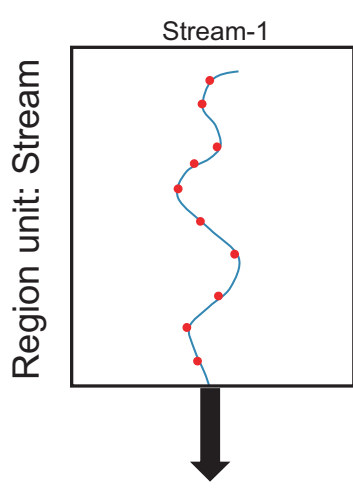

Beta diversity Habitat heterogeneity
Stream-2

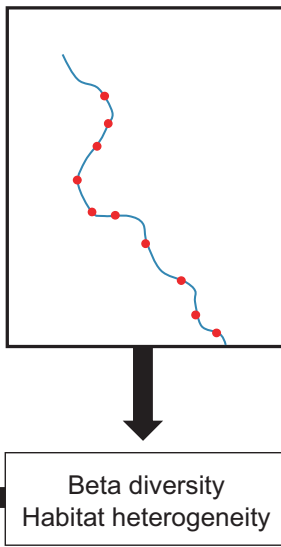

Stream-10

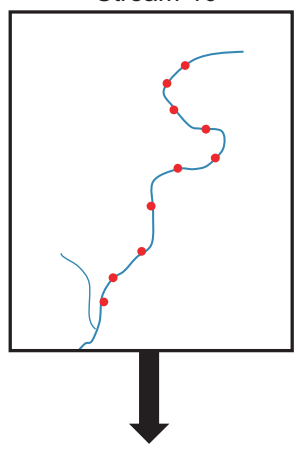

Beta diversity Habitat heterogeneity

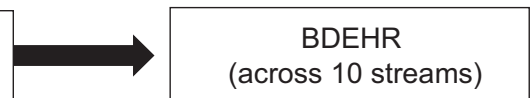

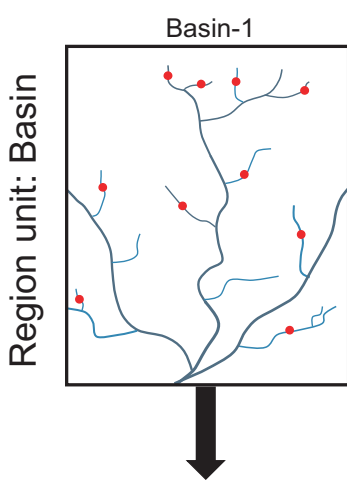

Beta diversity Habitat heterogeneity
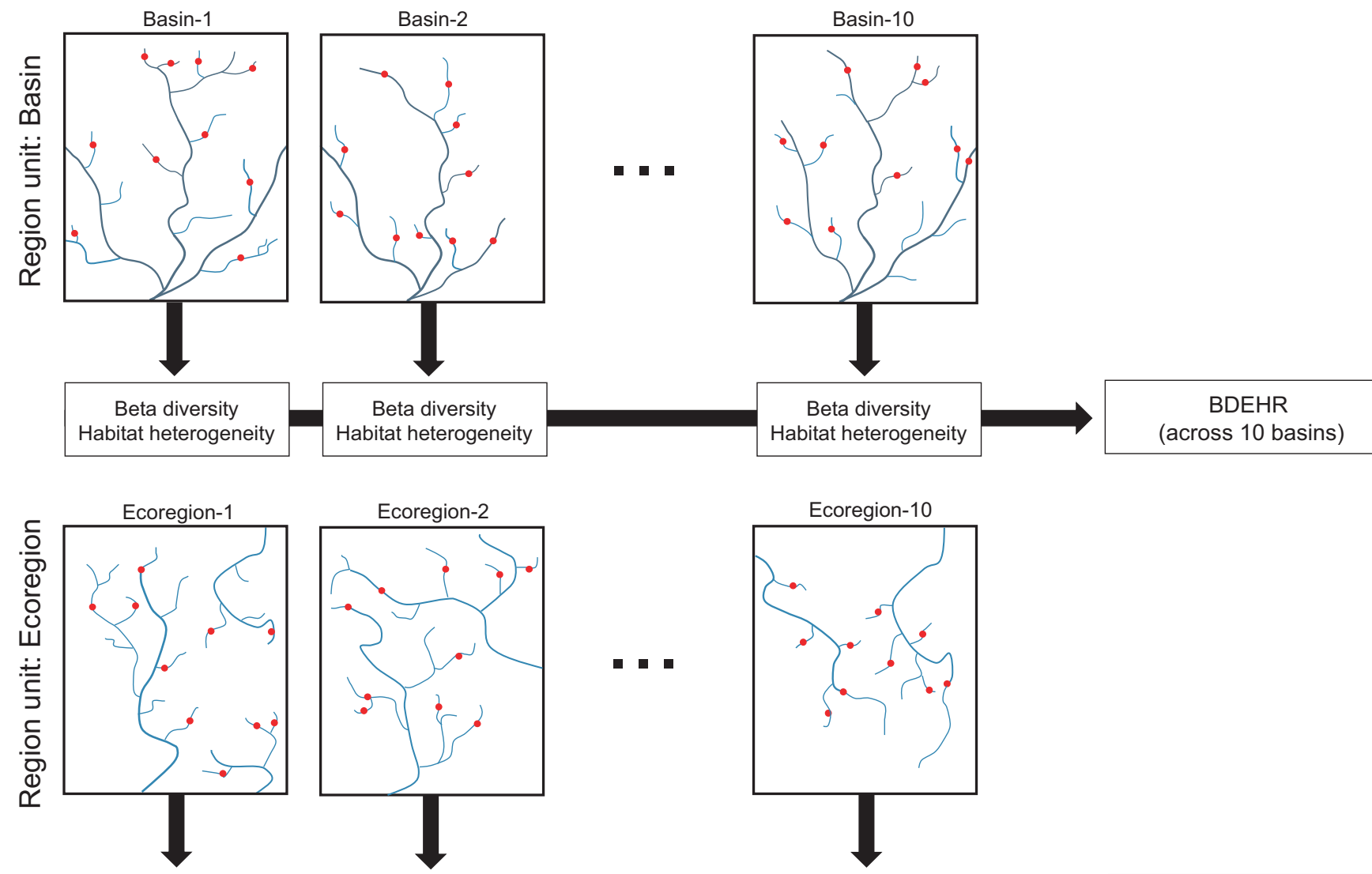

Beta diversity
abitat heterogeneity

Beta diversity Habitat heterogeneity

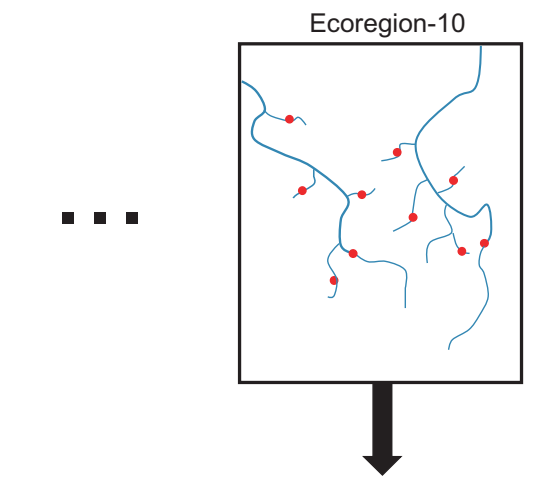

Beta diversity Habitat heterogeneity

BDEHR

(across 10 ecoregions)

Fig. 1 A schematic representation of different region unit levels in running waters. In these hypothetical examples, there are 10 stream region units each with 10 localities; or 10 basin region units each with 10 localities; or 10 ecoregion region units each with 10 localities. For each region unit, average biological distance (beta diversity) and average environmental distance (environmental heterogeneity) from localities to the respective region unit centroid are measured. Subsequently, beta diversity is regressed on environmental heterogeneity, leading to a measure of the strength of the BDEHR.

small region units (i.e. within a stream), decoupling the match between variation in species composition and variation in habitat conditions (Heino \& Grönroos, 2013). Correspondingly, within very large region units (i.e. within a large ecoregion), dispersal limitation may partly prevent species sorting from occurring, leading to less clear relationships between variation in species composition and variation in environmental conditions among 


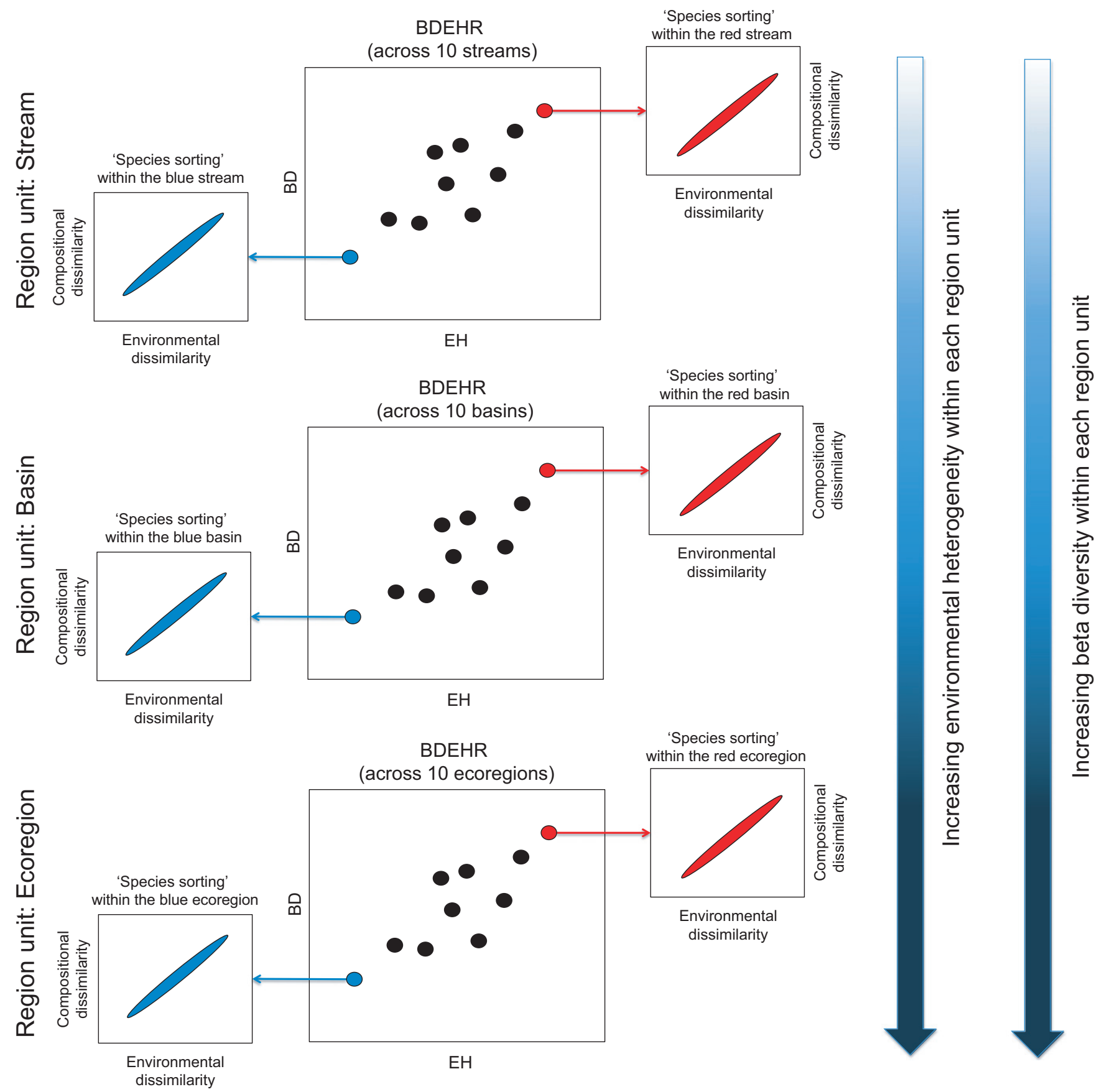

Fig. 2 The environmental control model underlying the beta diversity-environmental heterogeneity relationship (BDEHR). This model assumes that dispersal rates are similar irrespective of the spatial level of a region unit (stream versus basin versus ecoregion) and that species sorting is the sole mechanism driving compositional differences among localities within each region unit under consideration. This is illustrated by the strong relationships between compositional and environmental dissimilarities within each region unit irrespective of whether beta diversity and environmental heterogeneity are low ('blue' region unit) or high ('red' region unit).

localities. In contrast, if dispersal rates are neither too high nor clearly limiting among localities (i.e. within a drainage basin), species sorting should lead to strong associations between species composition and habitat conditions. This is the dispersal-environmental control model' underlying the BDEHR tested across multiple region units (Fig. 3). This model also starts from the individual region unit level, where species sorting occurs among localities. However, in contrast to the environmental control model, high or low dispersal rates 


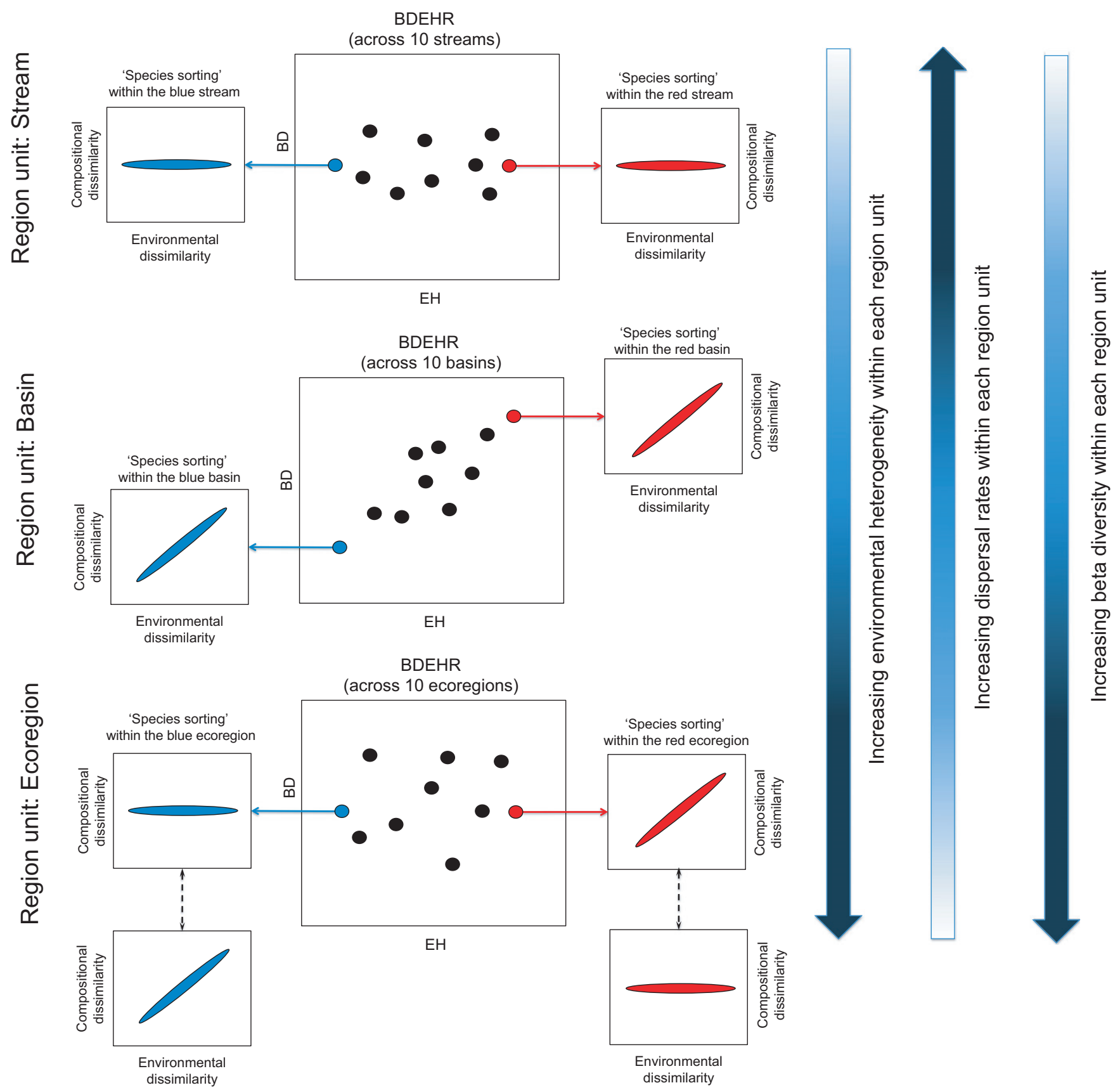

Fig. 3 The dispersal-environmental control model underlying the beta diversity-environmental heterogeneity relationship (BDEHR). This model assumes that dispersal rates decrease with increasing spatial level of a region unit (stream $>$ basin $>$ ecoregion) and affect amonglocality variation within each region unit, although environmental heterogeneity increases with increasing spatial extent (stream $<$ basin $<$ ecoregion). Species sorting is important, but its effect manifests best at intermediate dispersal rates (see text for details).

may partly disassociate communities from environmental control at small (i.e. within a stream) and large (i.e. within an ecoregion) spatial extents, respectively. If this model holds within each region unit, one should see different BDEHRs depending on the spatial level of the region units where beta diversity and environmental heterogeneity are measured (i.e. stream versus drainage basin versus ecoregion).
Ecologists have recently broadened their focus to not only quantify patterns of beta diversity across spatial scales, but also explain variation or dissimilarities in species composition using environmental variables or environmental dissimilarities, respectively (Legendre, Borcard \& Peres-Neto, 2005; Tuomisto \& Ruokolainen, 2006; Melo, Rangel \& Diniz-Filho, 2009; Anderson et al., 2011). Various statistical approaches have hence been 
proposed to disentangle the effects of spatial processes and species sorting on community structure, including (1) variation partitioning in constrained ordination analysis (Legendre et al., 2005), (2) partial regression of distance matrices (Tuomisto \& Ruokolainen, 2006) and (3) test of the homogeneity of multivariate dispersions (Anderson et al., 2006). This latter test also provides a measure of beta diversity for each region unit (i.e. average distance from localities to a region unit centroid) that can be used in further analyses (Anderson et al., 2011). These three methods are intended to (1) model variation in raw community composition among sites as functions of environmental and spatial predictors, (2) model compositional dissimilarities between sites using geographical and environmental distance matrices and (3) quantify community compositional variation or environmental heterogeneity among localities within a region unit. Subsequently, a relationship between the resulting beta diversity and environmental heterogeneity values (obtained using the third method) can be tested across multiple region units (Anderson et al., 2006). While most studies examining running water systems have used (1) and (2) to infer the relative roles of spatial processes and environmental filtering for variation in community composition (Landeiro et al., 2012; Göthe et al., 2013; Grönroos et al., 2013), few studies have applied (3) to tackle basically the same question but from a different point of view (Heino et al., 2013; Astorga et al., 2014; Bini et al., 2014).

We focus on unifying the terminology and reconciling the different patterns of the BDEHR by considering the spatial level of a region unit and underlying mechanisms in running waters. We describe the two conceptual models (i.e. the environmental control model and the dispersal-environmental control model), akin to the previous ideas of Leibold et al. (2004) of metacommunity organisation, and adapt those ideas to studying the BDEHR in running water systems. We illustrate the scale dependency of the mechanisms underlying this relationship by comparing the predictions of the two conceptual models with the findings of three recent BDEHR studies from stream systems (Heino et al., 2013; Astorga et al., 2014; Bini et al., 2014). These three studies used the same spatial grain (i.e. a riffle site), but were based on distinct spatial levels of the region units (i.e. stream versus basin versus ecoregion). Also, they employed basically the same analytical methods, which involved a regression between average biological distance from riffle sites to region unit centroid (i.e. beta diversity, the response variable) and average environmental distance from riffle sites to region unit centroid (i.e. environmental heterogeneity, the predictor variable) across multiple region units (see Table S1 in Supporting Information). They pursued the same question, but ended up with different conclusions. We suggest that the different patterns are probably due to the fact that underlying mechanisms vary with the spatial level of a region unit or, more specifically, from the stream level through the drainage basin level to the ecoregion level. We first consider potential analytical differences among the studies of Heino et al. (2013), Astorga et al. (2014) and Bini et al. (2014) and then provide two hypotheses regarding the effects of spatial scale on beta diversity patterns and underlying community assembly mechanisms.

\section{Analytical details}

The detection of beta diversity patterns may be affected by statistical choices regarding how to quantify beta diversity and environmental heterogeneity, and what biological and environmental variables to include in the analyses. First, if a study omits a diverse taxonomic group (e.g. Diptera: Chironomidae) from the analyses, the results may not be strictly comparable to those of other studies. Second, the choices of how many and which environmental variables are used for quantifying environmental heterogeneity may affect the comparability of the results. Although the measures of beta diversity and environmental heterogeneity were derived using the same approach (i.e. average distance from localities to a region unit centroid) and distance measures (i.e. Sørensen dissimilarity coefficient for presenceabsence data and standardised Euclidean distance for environmental data), there were some differences in the methodological choices and data set characteristics (Table S1) between the studies of Heino et al. (2013), Astorga et al. (2014) and Bini et al. (2014). For example, Astorga et al. (2014) omitted chironomid midges and focused only on selected key environmental variables for calculating environmental heterogeneity, whereas Heino et al. (2013) and Bini et al. (2014) included midges and tested the effect of overall environmental heterogeneity on beta diversity.

We re-analysed the data of Heino et al. (2013) by (1) omitting chironomid midges that are rarely included in these types of studies and (2) by calculating environmental heterogeneity based only on five key variables. These additional analyses were also based on average Sørensen distance from localities to centroid for biological data and average standardised Euclidean distance from localities to centroid for environmental data, following exactly the 
same statistical methodology as in the three original studies. Key environmental variables measured for each locality included channel width, shading, current velocity, depth and moss cover, which often influence stream invertebrate communities at this combination of spatial grain and spatial extent in boreal regions (Heino \& Korsu, 2008; Grönroos \& Heino, 2012; Heino et al., 2013) and elsewhere (Robson \& Barmuta, 1998; Robson \& Chester, 1999; Rackemann et al., 2013). We found no differences in relation to the patterns originally detected by Heino et al. (2013), and the BDEHRs remained far from significant in all cases (see Fig. S1 in Supporting Information). Finally, the ranges in average environmental distance from localities to a region unit centroid were similar among the three studies, being 2.42-3.74, 1.44-2.75 and 2.74-5.40 for Heino et al. (2013), Astorga et al. (2014) and Bini et al. (2014), respectively. The small differences in these figures are unlikely to account for the different BDEHR patterns. The reason for different findings among the studies of Heino et al. (2013), Astorga et al. (2014) and Bini et al. (2014) is hence unlikely to be related to statistical choices or data set characteristics. More likely explanations for the differences among studies are related to differences in the spatial level of the region units and scale dependency in the mechanisms underlying spatial variation of beta diversity.

\section{Hypothesis one: Beta diversity patterns change with} spatial scale

The BDEHR was very strong $\left(R^{2}=0.95\right)$ in the study by Astorga et al. (2014), which encompassed drainage basins as region units. However, it was not significant in the studies by Heino et al. (2013) and Bini et al. (2014), which encompassed streams and ecoregions as region units, respectively. Furthermore, another study that tested for the BDEHR also suggested that within-stream beta diversity was not related to within-stream environmental heterogeneity across multiple streams in a tropical forest system (Al-Shami et al., 2013), being in line with the findings from boreal streams at the same spatial unit level (Heino et al., 2013). Hence, there needs to be some underlying mechanisms or, more generally, scale-dependent variations in mechanisms leading to different forms of the BDEHR.

\section{Hypothesis two: Mechanisms of community assembly are scale dependent}

The environmental control model (Fig. 2) assumes that species sorting is equally important at all region unit levels and that dispersal rates do not interfere with environmental filtering. If these two assumptions hold, we should see a positive BDEHR irrespective of the spatial level of the region unit used in the analysis. By contrast, if the dispersal-environmental control model (Fig. 3) holds, we should find strong species sorting among localities within a drainage basin because intermediate dispersal rates at this region unit level result in the strongest community-environment relationships. Consequently, a positive BDEHR should occur when it is tested using multiple drainage basins (see the middle panel of Fig. 3), whereas we should see no or only a weak BDEHR when multiple streams (see the upper panel of Fig. 3) or multiple ecoregions (see the bottom panel of Fig. 3) are used as region units. This is because high dispersal rates (i.e. mass effects) among localities within a stream may interfere with species sorting (Heino \& Grönroos, 2013), whereas dispersal limitation among localities within a large ecoregion may preclude perfect species sorting and lead to variation in the strength of species sorting among different ecoregions (Bini et al., 2014). The dispersal-environmental control model is actually indirectly supported by comparison of the studies by Heino et al. (2013), Astorga et al. (2014) and Bini et al. (2014). It has to be noted, however, that there always needs to be enough variation in beta diversity and environmental heterogeneity for a positive BDEHR to be possible when tested using multiple region units. This was the case in all three studies. However, the match between communities and the environmental conditions within each region unit probably differed among the three studies, leading to the differences in their BDEHRs. Further support for the dispersal-environmental control model has been found in studies emphasising the interactive effects of species sorting and dispersal processes on stream communities, and that potential dispersal distances vary among species (Downes, Bellgrove \& Street, 2005; Hughes, 2007; Finn et al., 2011; Grönroos et al., 2013). Hence, stream communities are not ideally structured by species sorting alone and the environmental control model is likely to fail when applied at different spatial scales.

\section{Reconciliation, caveats and the importance of a unified terminology}

By first proposing two conceptual models, we showed that the spatial level of region units is likely to affect both environmental gradient lengths and ecological mechanisms driving spatial variation in species composition within a region unit. A large body of research on 
community patterns of stream organisms suggests that species sorting mainly drives spatial variation in community composition among localities within a drainage basin (Clarke et al., 2008; Landeiro et al., 2012; Siqueira et al., 2012; Göthe et al., 2013; Grönroos et al., 2013). However, a growing body of work on small (i.e. within localities) to medium (i.e. among localities or among streams) scale processes, including dispersal and colonisation processes, shows that stream invertebrates may actually be more dispersal limited than has been commonly believed (Hughes, 2007; Hughes, Schmidt \& Finn, 2009). Furthermore, recent empirical studies have increasingly shown that other processes, such as oviposition choices, can leave lasting effects on distribution patterns of stream invertebrates at the among-localities scale within a stream (Lancaster, Downes \& Arnold, 2011; Heino \& Peckarsky, 2014). It is also likely, however, that the importance of dispersal limitation increases when a study spans localities of many drainage basins within an ecoregion (Hoeinghaus, Winemiller \& Birnbaum, 2007; Mykrä et al., 2007; Jacquemin \& Pyron, 2011; Maloney \& Munguia, 2011; Astorga et al., 2012). In addition, while some empirical studies from stream systems have shown that high dispersal rates do not necessarily interfere with species sorting at small microhabitat scales (Robson \& Chester, 1999; Heino \& Korsu, 2008), theory and other empirical studies suggest that the match between community composition and environmental conditions is weakened by high dispersal rates among localities within a stream (Leibold et al., 2004; Heino \& Grönroos, 2013).

If scale dependencies are general phenomena, one should first find the strongest role for species sorting among localities within a drainage basin, species sorting masked by high dispersal rates among localities within a stream, and the strength of species sorting weakened within a large ecoregion (see the bottom panel of Fig. 3), leading to wide variation in the strength of species sorting among different ecoregions (Bini et al., 2014). These differences in the underlying mechanisms active within each region unit should lead to differences in the BDEHR that can only be tested using multiple region units, reconciling the different findings from running water systems.

We emphasise, however, that the two conceptual models we present are idealistic, and the fit of empirical data with the models is likely to be affected by contingencies in regional history, landscape characteristic, species pools and the dispersal abilities of the organisms studied. For example, genetic studies have suggested that dispersal distances vary considerably among species of aquatic insects (Hughes, 2007; Finn et al., 2011), implying that dispersal is a key factor affecting BDEHRs. Furthermore, different organismal groups show different dispersal modes, distances and rates (Beisner et al., 2006; Hugueny, Oberdorff \& Tedesco, 2010; Maloney \& Munguia, 2011; Astorga et al., 2012; De Bie et al., 2012; Heino et al., 2012), which is likely to affect the spatial level of a region unit where species sorting is manifested most strongly (Heino \& Peckarsky, 2014). We may assume that, for organisms showing very limited dispersal rates and short dispersal distances, the strongest BDEHRs may be detected when tested using multiple stream region units. On the other hand, for organismal groups with very high dispersal rates and large dispersal distances, the strongest BDEHRs might be expected to occur when tested using multiple ecoregion region units. Accordingly, we encourage freshwater ecologists to consider spatial scale explicitly in their studies. Such a consideration is important because not only environmental gradient lengths, but also the mechanisms affecting ecological communities and the spatial variation of beta diversity vary with the spatial level of a region unit and organismal group (Shurin, Cottenie \& Hillebrand, 2009; Angeler \& Drakare, 2013; Heino, 2013). These mechanisms may thus be better inferred if we acquire more knowledge on the life histories of aquatic organisms, which should elucidate the processes that underpin BDHERs across multiple spatial scales.

There are some potential issues with these interpretations. First, quantifications of beta diversity are potentially affected by the dissimilarity measure used and whether presence-absence or abundance data are used (Koleff, Gaston \& Lennon, 2003; Anderson et al., 2006; Baselga, 2013). Among the three empirical studies we considered in detail, Heino et al. (2013) and Bini et al. (2014) ran separate analyses for both presence-absence and abundance data, but their conclusions did not change with a change in numerical resolution. In contrast, Astorga et al. (2014) used only presence-absence data and, hence, we cannot infer if changing numerical resolution would have affected their conclusions. Mentioning the numerical resolution used is very important in these types of studies, because it may potentially affect our conclusions more than a change in taxonomic resolution (Anderson et al., 2006, 2011; Heino, 2008, 2014). Second, the criteria used for selecting variables in the calculation of environmental heterogeneity may affect the BDEHR, and researchers should always mention whether they aimed to examine environmental heterogeneity based on overall environmental heterogeneity in a region unit without a pre-selection of variables 
Table 2 A unified terminology related to the examination of the BDEHR based on average distance from localities to a region unit centroid. Note that the distance of an individual locality to a region unit centroid is not a suitable measure of beta diversity or environmental heterogeneity per se, but depicts the deviation of an individual locality from 'a typical locality' in a region unit

\begin{tabular}{|c|c|c|c|c|c|}
\hline Level & $\begin{array}{l}\text { Example } \\
\text { level }\end{array}$ & $\begin{array}{l}\text { Biological } \\
\text { measure }\end{array}$ & $\begin{array}{l}\text { Environmental } \\
\text { measure }\end{array}$ & Data points & $\begin{array}{l}\text { Focus of a } \\
\text { study }\end{array}$ \\
\hline Region unit & $\begin{array}{l}\text { Stream or basin } \\
\text { or ecoregion }\end{array}$ & $\begin{array}{l}\text { Beta diversity for } \\
\text { a region unit }\end{array}$ & $\begin{array}{l}\text { Environmental } \\
\text { heterogeneity } \\
\text { for a region unit }\end{array}$ & $\begin{array}{l}\text { Single value of beta } \\
\text { diversity or } \\
\text { environmental } \\
\text { heterogeneity } \\
\text { for each region unit }\end{array}$ & BDEHR \\
\hline
\end{tabular}

(Heino et al., 2013) or whether they examined various subsets of environmental variables separately for calculating environmental heterogeneity (Bini et al., 2014) or, finally, whether they directly focused on a set of key environmental variables known to have strong effects on the biota (Astorga et al., 2014). We recommend that researchers use both a measure of overall heterogeneity and a measure of environmental heterogeneity based on a set of key environmental variables. Although our additional analyses did not reveal differences in the BDHERs based on either measure of environmental heterogeneity (Fig. S2), differences among the measures are also possible.

Our understanding of the BDEHR may also be hampered by inconsistent terminology. We propose that the term BDEHR should only be used if there are multiple region units for which both beta diversity (as average biological distance from individual localities to a region unit centroid) and environmental heterogeneity (as average environmental distance from individual localities to a region unit centroid) are measured. We also emphasise that regressing the biological distances of each locality to a region unit centroid on the environmental distance of each locality to a region unit centroid is not related to testing the BDEHR (Table 2). Rather, such analyses are more directly related to examining variation in the degree of community deviation explained by variation in the degree of environmental deviation across a set of sites. These analyses are actually closer to explaining variation in local community composition by a set of local environmental predictors rather than related to testing the BDEHR. To this end, we hope that a unified terminology on the BDEHR will help communication among researchers studying biodiversity in running waters.

\section{Implications}

We reiterate the opinion that issues related to spatial scale will always be the 'final frontier' in ecology (Levin, 1992). On the one hand, these issues often preclude making broad generalisations spanning multiple spatial scales, as exemplified above. On the other hand, acknowledging the importance of scale dependencies in generating variation in ecological patterns and underlying mechanisms is the key for advancing our discipline. The choice of spatial level of a region unit, which relates to the length of the environmental gradients and dispersal processes, is also crucial in an important, albeit often neglected, aspect of research on biodiversity in running waters. Although we need biological and environmental variability within each region unit to test the BDEHR across multiple region units, caution should be exercised to prevent mixing of different regional species pools and physiographic provinces. Such mixing would increase beta diversity and environmental heterogeneity within a region unit but, at the same time, obscure the mechanisms affecting variation in species composition among localities within a region unit. This is because most species in the species pool would not be able to disperse to all localities within a region unit and, hence, historical legacies and unsurmountable dispersal barriers would interfere with the ecological mechanisms discussed in our conceptual models.

\section{Acknowledgments}

Our research on community ecology and running waters has been continuously supported by the Academy of Finland and the Brazilian Council of Science and Technology (CNPq). We thank Colin Townsend and two 
anonymous reviewers for excellent comments that improved this paper.

\section{References}

Al-Shami S.A., Heino J., Che Salmah M.R., Ahmad A.H., Hamid S.A. \& Madrus M.R. (2013) Drivers of beta diversity of macroinvertebrate communities in tropical forest streams. Freshwater Biology, 58, 1126-1137.

Altermatt F. (2013) Diversity in riverine metacommunities: a network perspective. Aquatic Ecology, 47, 365-377.

Anderson M.J., Crist T.O., Chase J.M., Vellend M., Inouye B.D., Freestone A.L. et al. (2011) Navigating the multiple meanings of $\beta$ diversity: a roadmap for the practicing ecologist. Ecology Letters, 14, 19-28.

Anderson M.J., Ellingsen K.E. \& McArdle B.H. (2006) Multivariate dispersion as a measure of beta diversity. Ecology Letters, 9, 683-693.

Angeler D.G. \& Drakare S. (2013) Tracing alpha, beta and gamma diversity responses to environmental change in boreal lakes. Oecologia, 172, 1191-1202.

Astorga A., Death R., Death F., Paavola R., Chakraborty M. \& Muotka T. (2014) Habitat heterogeneity drives the geographical distribution of beta diversity: the case of New Zealand stream invertebrates. Ecology and Evolution, 4, 2693-2702.

Astorga A., Oksanen J., Soininen J., Virtanen R., Luoto M. \& Muotka T. (2012) Distance decay of similarity in stream communities: do macro- and microorganism follow the same rules? Global Ecology and Biogeography, 21, 365-375.

Bar-Massada A. \& Wood E.M. (2014) The richness-heterogeneity relationship differs between heterogeneity measures within and among habitats. Ecography, 37, 528-535.

Barton P.S., Cunningham S.A., Manning A.D., Gigg H., Lindenmayer D.B. \& Didham R.K. (2013) The spatial scaling of beta diversity. Global Ecology and Biogeography, 22, 639-647.

Baselga A. (2013) Multiple site dissimilarity quantifies compositional heterogeneity among several sites, while average pairwise dissimilarity may be misleading. Ecography, 36, 124-128.

Beisner B.E., Peres-Neto P.R., Lindstrom E., Barnett A. \& Longhi M.L. (2006) The role of dispersal in structuring lake communities from bacteria to fish. Ecology, 87, 2895-2991.

Bini L.M., Landeiro V.L., Padial A.A., Siqueira T. \& Heino J. (2014) Nutrient enrichment is related to two facets of beta diversity for stream invertebrates across the United States. Ecology, 95, 1569-1578.

Brown B.L., Swan C.M., Auerbach D.A., Grant E.H.C., Hitt N.P., Maloney K.O. et al. (2011) Metacommunity theory as a multispecies, multiscale framework for studying the influence of river network structure on riverine communities and ecosystems. Journal of the North American Benthological Society, 30, 310-327.
Chase J.M. \& Leibold M.A. (2003) Ecological Niches. Chicago University Press, Chicago.

Clarke A., Mac Nally R., Bond N. \& Lake P.S. (2008) Macroinvertebrate diversity in headwater streams: a review. Freshwater Biology, 53, 1707-1721.

Cottenie K. (2005) Integrating environmental and spatial processes in ecological community dynamics. Ecology Letters, 8, 1175-1182.

Datry T., Larned S.T., Fritz K.M., Bogan M.T., Wood P.J., Meyer E.I. et al. (2014) Broad-scale patterns of invertebrate richness and community composition in temporary rivers: effects of flow intermittence. Ecography, 37, 94-104.

De Bie T., De Meester L., Brendonck L., Martens K., Goddeeris B., Ercken D. et al. (2012) Body size and dispersal mode as key traits determining metacommunity structure of aquatic organisms. Ecology Letters, 15, 740-747.

Downes B.J., Lake P.S., Schreiber E.S.G. \& Glaister A. (1998) Habitat structure and the regulation of local species diversity in a stony upland stream. Ecological Monographs, 68, 237-257.

Downes B.J., Bellgrove A. \& Street J.L. (2005) Drifting or walking? Colonisation routes used by different instars and species of lotic, macroinvertebrate filter-feeders. Marine E Freshwater Research, 56, 815-824.

Downes B.J. \& Lancaster J. (2010) Does dispersal control population densities in advection dominated systems? Journal of Animal Ecology, 79, 235-248.

Downes B.J. \& Reich P. (2008) What is the spatial structure of stream insect populations? Dispersal behaviour at different life-history stages. In: Aquatic Insects: Challenges to Populations. (Eds J. Lancaster \& R.A. Briers), pp. 184-203. CAB International Publishers, Wallingford.

Finn D.S., Bonada N., Murria C. \& Hughes J.M. (2011) Small but mighty: headwaters are vital to stream network biodiversity at two levels of organization. Journal of North American Benthological Society, 30, 963-980.

Gering J.C. \& Crist T.O. (2002) The alpha-beta-regional relationship: providing new insights into local-regional patterns of species richness and scale dependence of diversity components. Ecology Letters, 5, 433-444.

Göthe E., Angeler D.G. \& Sandin L. (2013) Metacommunity structure in a small boreal stream network. Journal of Animal Ecology, 82, 449-458.

Gravel D., Canham C.D., Beaudet M. \& Messier C. (2006) Reconciling niche and neutrality: the continuum hypothesis. Ecology Letters, 9, 399-409.

Grönroos M. \& Heino J. (2012) Species richness at the guild level: effects of species pool and local environmental conditions on stream macroinvertebrate communities. Journal of Animal Ecology, 81, 679-691.

Grönroos M., Heino J., Siqueira T., Landeiro V.L., Kotanen J. \& Bini L.M. (2013) Metacommunity structuring in stream networks: roles of dispersal mode, distance type 
and regional environmental context. Ecology and Evolution, 3, 4473-4487.

Harrison S., Ross S.J. \& Lawton J.H. (1992) Beta diversity on geographic gradients in Britain. Journal of Animal Ecology, 61, 151-158.

Heino J. (2008) Influence of taxonomic resolution and data transformation on biotic matrix concordance and assemblage-environment relationships in stream macroinvertebrates. Boreal Environment Research, 13, 359-369.

Heino J. (2011) A macroecological perspective of diversity patterns in the freshwater realm. Freshwater Biology, 56, 1703-1722.

Heino J. (2013) The importance of metacommunity ecology for environmental assessment research in the freshwater realm. Biological Reviews, 88, 166-178.

Heino J. (2014) Taxonomic surrogacy, numerical resolution and responses of stream macroinvertebrate communities to ecological gradients: are the inferences transferable among regions? Ecological Indicators, 36, 186-194.

Heino J. \& Grönroos M. (2013) Does environmental heterogeneity affect species co-occurrence in ecological guilds across stream macroinvertebrate metacommunities? Ecography, 36, 926-936.

Heino J., Grönroos M., Ilmonen J., Karhu T., Niva M. \& Paasivirta L. (2013) Environmental heterogeneity and beta diversity of stream macroinvertebrate communities at intermediate spatial scales. Freshwater Science, 32, 142-154.

Heino J., Grönroos M., Soininen J., Virtanen R. \& Muotka T. (2012) Context dependency and metacommunity structuring in boreal headwater streams. Oikos, 121, 537-544.

Heino J. \& Korsu K. (2008) Testing species-stone area and species-bryophyte cover relationships in riverine macroinvertebrates at small scales. Freshwater Biology, 53, 558-568.

Heino J. \& Peckarsky B.L. (2014) Integrating behavioral, population and large-scale approaches for understanding stream insect communities. Current Opinion in Insect Science, 2, 7-13.

Hepp L.U. \& Melo A.S. (2013) Dissimilarity of stream insect assemblages: effects of multiple scales and spatial distances. Hydrobiologia, 703, 239-246.

Hoeinghaus D.J., Winemiller K.O. \& Birnbaum J.S. (2007) Local and regional determinants of stream fish assemblage structure: inferences based on taxonomic versus functional groups. Journal of Biogeography, 34, 324-338.

Hughes J.M. (2007) Constraints on recovery: using molecular methods to study connectivity of aquatic biota in rivers and streams. Freshwater Biology, 52, 616-631.

Hughes J.M., Schmidt D.J. \& Finn D.S. (2009) Genes in streams: using DNA to understand the movement of freshwater fauna and their riverine habitat. BioScience, 59, 573-583.

Hugueny H., Oberdorff T. \& Tedesco P.A. (2010) Community ecology of river fishes: a large scale perspective. American Fisheries Society Symposium, 73, 29-62.
Jackson D.A., Peres-Neto P.R. \& Olden J.D. (2001) What controls who is where in freshwater fish communities the roles of biotic, abiotic and spatial factors. Canadian Journal of Fisheries and Aquatic Sciences, 58, 157-170.

Jacquemin S.J. \& Pyron M. (2011) Impact of past glaciations events on contemporary fish assemblages of the Ohio River basin. Journal of Biogeography, 38, 982-991.

Koleff P., Gaston K.J. \& Lennon J.J. (2003) Measuring beta diversity for presence-absence data. Journal of Animal Ecology, 72, 367-382.

Lancaster J.Downes B.J. \& Arnold A. (2011) Lasting effects of maternal behaviour on the distribution of a dispersive stream insect. Journal of Animal Ecology, 80, 10611069.

Landeiro V.L., Bini L.M., Melo A.S., Pes A.M.O. \& Magnusson W.E. (2012) The roles of dispersal limitation and environmental conditions in controlling caddisfly (Trichoptera) assemblages. Freshwater Biology, 57, 1554-1564.

Legendre P., Borcard D. \& Peres-Neto P.R. (2005) Analyzing beta diversity: partitioning the spatial variation of community composition data. Ecological Monographs, 75, 435-450.

Leibold M.A., Holyoak M., Mouquet N., Amarasekare P., Chase J.M., Hoopes M.F. et al. (2004) The metacommunity concept: a framework for multi-scale community ecology. Ecology Letters, 7, 601-613.

Levin S.A. (1992) The problem of pattern and scale in ecology. Ecology, 73, 1943-1967.

Maloney K.O. \& Munguia P. (2011) Distance decay of similarity in temperate aquatic communities: effects of environmental transition zones, distance measure, and life histories. Ecography, 34, 287-295.

Melo A.S., Rangel T.F.L.V.B. \& Diniz-Filho J.A.F. (2009) Environmental drivers of beta diversity patterns in NewWorld birds and mammals. Ecography, 32, 226-236.

Melo A.S., Schneck F., Hepp L.U., Simões N.R., Siqueira T. \& Bini L.M. (2011) Focusing on variation: methods and applications of the concept of beta diversity in aquatic ecosystems. Acta Limnologica Brasiliensia, 23, 318-331.

Mykrä H., Heino J. \& Muotka T. (2007) Scale-related patterns in the spatial and environmental components of stream macroinvertebrate assemblage variation. Global Ecology and Biogeography, 16, 149-159.

Ng I.S.Y., Carr C. \& Cottenie K. (2009) Hierarchical zooplankton metacommunities: distinguishing between high and limiting dispersal mechanisms. Hydrobiologia, 619, 133-143.

Rackemann S., Robson B. \& Matthews T. (2013) Conservation value of waterfalls as habitat for lotic insects of western Victoria, Australia. Aquatic Conservation: Marine and Freshwater Ecosystems, 23, pages 171-178.

Robson B.J. (1996) Habitat architecture and trophic interaction strength in a river: riffle-scale effects. Oecologia, 107, 411-420.

(C) 2014 John Wiley \& Sons Ltd, Freshwater Biology, 60, 223-235 
Robson B.J. \& Barmuta L.A. (1998) The effect of two scales of habitat architecture on benthic grazing in a river. Freshwater Biology, 39, 207-220.

Robson B.J. \& Chester E.T. (1999) Spatial patterns of invertebrate species richness in a river: the relationship between riffles and microhabitats. Austral Ecology, 24, 599-607.

Shurin J.B., Cottenie K. \& Hillebrand H. (2009) Spatial autocorrelation and dispersal limitation in freshwater organisms. Oecologia, 159, 151-159.

Siqueira T., Bini L.M., Roque F.O., Pepinelli M., Ramos R.C., Marques Couceiro S.R. et al. (2012) Common and rare species respond to similar niche processes in macroinvertebrate metacommunities. Ecography, 35, 183-192.

Thompson R.M. \& Townsend C.R. (2006) A truce with neutral theory: local deterministic factors, species traits and dispersal limitation together determine patterns of diversity in stream invertebrates. Journal of Animal Ecology, 75, 476-484.

Tuomisto H. (2010) A diversity of beta diversities: straightening up a concept gone awry. Part 1. Defining beta diversity as a function of alpha and gamma diversity. Ecography, 33, 2-22.

Tuomisto H. \& Ruokolainen K. (2006) Analyzing or explaining beta diversity? Understanding the targets of different methods of analysis. Ecology, 87, 2697-2708.

Van der Gucht K., Cottenie K., Muylaert K., Vloemans N., Cousin S., Declerck S. et al. (2007) The power of species sorting: local factors drive bacterial community composition over a wide range of spatial scales. Proceedings of the National Academy of Sciences, 104, 20404-20409.

Whittaker R.H. (1960) Vegetation of the Siskiyou Mountains, Oregon and California. Ecological Monographs, 30, 279-338.

Wiens J.A. (1989) Spatial scaling in ecology. Functional Ecology, 3, 385-397.

Winegardner A.K., Jones B.K., Ng I.S.Y., Siqueira T. \& Cottenie K. (2012) The terminology of metacommunity ecology. Trends in Ecology and Evolution, 27, 253-254.

Wu J. \& Loucks O.L. (1995) From balance of nature to hierarchical patch dynamics: a paradigm shift in ecology. The Quarterly Review of Biology, 70, 439-466.

\section{Supporting Information}

Additional Supporting Information may be found in the online version of this article:

Table S1. Comparisons of three recent empirical studies on the BDEHR in stream invertebrates.

Figure S1. A test of the effect of using all environmental variables and key environmental variables only for calculating environmental heterogeneity among sites.

(Manuscript accepted 11 October 2014) 